Article

\title{
Aging-Suitability of Urban Waterfront Open Spaces in Gongchen Bridge Section of the Grand Canal
}

\author{
Min Gong ${ }^{1}$, Mengyu Ren ${ }^{2}$, Qin Dai ${ }^{1}$ and Xiaoyu Luo ${ }^{2, *}$ \\ 1 Department of Architecture, Zhejiang University City College, Hangzhou 310058, China; \\ gongm@zucc.edu.cn (M.G.); daiqin@chinagreentown.com (Q.D.) \\ 2 College of Civil Engineering and Architecture, Zhejiang University, Hangzhou 310058, China; \\ 3140102961@zju.edu.cn \\ * Correspondence: xiaoyuluo@zju.edu.cn; Tel.: +86-135-8814-0937
}

Received: 17 September 2019; Accepted: 16 October 2019; Published: 1 November 2019

check for updates

\begin{abstract}
Aging has become a worldwide issue in the 21st century. China became an aging society in 1999, and home-based care is now the main mode of care for the elderly. Present research on the aging-suitability of spaces mainly focuses on the interior and exterior environmental conditions of the home, ignoring public open spaces at the regional and urban levels, with a specific lack of research on waterfront open spaces, which is an important type of public open space in Jiangnan Watertown. The study used the example of the waterfront space of the Hangzhou Gongchen Bridge section of the Grand Canal, the longest artificial canal in the world, to analyze the aging-suitability of waterfront open spaces. Firstly, in this section, the activity characteristics of the elderly were surveyed through observation and semi-structured interviews, then the subjective satisfaction of the elderly with the waterfront spaces was investigated. Through correlation and principal component analysis, five common factors affecting the satisfaction of the elderly were obtained: environment, function, transportation, social culture, and vision. Finally, some design suggestions suitable for the elderly were proposed for three aspects: environment, function, and transportation, which are the most important factors affecting the overall subjective satisfaction of the elderly with the waterfront open space. This study provided a reference for the design and planning of aging-friendly waterfront open spaces, which would improve the aging-suitability of urban open spaces, increasing social participation, and enhancing the quality of life of the elderly. It is of profound significance to build a senior-friendly city and deal with the increasingly severe aging problem.
\end{abstract}

Keywords: waterfront open space; suitability; subjective satisfaction; elderly

\section{Introduction}

Due to falling birth rates and increasing longevity, the world population is aging [1]. The proportion of citizens who are aged 60 or above will rise to $26.1 \%$ in the United States, $27.8 \%$ in the UK, and $37.3 \%$ in Japan by 2030 [2]. As a recent report from the Chinese Academy of Social Science [3] shows, China will be the country with the fastest aging population after Japan. By the end of 2016, the number of elderly people in China over the age of 60 reached 230 million, accounting for $16.7 \%$ of the total population. It is estimated that by 2050, the elderly population of Chinese people over 60 years old will reach 479 million, accounting for $35.1 \%$ of China's total population [4].

As the health of the elderly declines, the range of their activities shrinks, making them more dependent on their direct living environment for their activities [5,6]. Esther H. K. Yung et al. [7] reported that elderly people consider "social and physical activities", "social networks", and a "clean and pleasant environment", as well as "community life facilities and services", to be their most important needs. Parks and open spaces have been adjusted globally to provide a sense of belonging 
for the elderly, enhance social interaction, and create a sense of place attachment [8]. While, due to higher living density and inevitability in cities, more and more buildings are being built, and there is a threat of losing urban open space [9].

The current study about the aging-suitability of space mainly focused on residential areas. Philips et al. [10], Cristina Fernandez-Portero et al. [11], Yafei Liu et al. [12], and other scholars studied the residential satisfaction of the elderly from the perspective of internal environmental factors (including indoor lighting, ventilation, temperature, lighting in public places, and noise pollution) and external factors (including green spaces/parks, leisure places, neighborhoods). Results indicated that good housing, neighborhood quality, and a safe social environment contributed to better subjective, physical, and mental health conditions of older adults. Among them, indoor lighting and ventilation, and outdoor lighting and noise have a high impact. Zhen Zhang and Jianxin Zhang [13] used questionnaires and interviews to investigate the elderly's satisfaction with their living environments, and they used SPSS to analyze the results statistically. They found that the residential environment of the neighborhood and the Chinese elderly's physical health and income were the two most relevant factors influencing subjective well-being. Bingqiu Yan, Xiaolu Gao, and Michael Lyon [14] examined the satisfaction of seniors in relation to the elderly services and living environments available to them, through questionnaires and empirical studies of six types of neighborhoods in Beijing. The research showed that 'social support' (e.g., social relations and neighborhood communication) had the largest direct effect on satisfaction, followed by 'economic status' and 'service accessibility', implying that neighborhood relationships, social communication, and community activities were important to senior citizens.

A systematic literature review, based on an analysis of 44 peer-reviewed journal articles, conducted by Wen et al. [15] found that published studies focused primarily on elderly people's recreational activities in urban parks. Some studies discussed the single performance of urban parks. Esther Hiu Kwan Yung et al. [16] studied thermal perceptions of the elderly, their use patterns, and their satisfaction with open spaces. The results showed that the factors, which influence the elderly's thermal perceptions, varied in the winter and summer, and there was a significant association between thermal acceptability and satisfaction with open spaces. Yanping Duan et al. [17] investigated physical activity (PA) areas in parks and their use by the elderly in a Chinese (Hong Kong) and a German (Leipzig) city. Results demonstrated that trails were the most often used PA areas by the elderly, where the elderly walk (in both cities) or cycle (only in L). Moreover, park accessibility by walking is related to the use of parks by the elderly for PA. Some studies also mentioned multiple factors of the suitability of urban parks for the elderly. Esther H. K. Yung et al. [1] estimated an ordered logit model to see how the different factors contributed to the satisfaction the elderly derive from using public parks. Insights obtained from the results highlight that it is important to consider social networks, social ties, social connections, place attachment, and mobility when planning and designing public parks. Divya Subramanian and Arnab Jana [18] used field research and questionnaires to study 51 recreational open spaces across the three Indian cities of Mumbai, Bengaluru, and Chennai. The outcome of the study highlighted the high positive impact of the provision of amenities and universal design features of recreational open space on the perceived 'attractiveness' of the open space, resulting in greater usage by the elderly. A review by Rosso et al. [19] highlighted the positive impact of thoughtful design and accessibility of open spaces on the perceived sense of safety, movement profiles, and PA levels in the elderly.

As an important part of public open spaces in a city, a waterfront open space bears the same function as a park but also has its unique charm. A waterfront open space, located between the land and water, is an area with both natural and artificial landscapes, which can enhance the accessibility and intimacy between people and nature. The linear and boundary features of waterfront spaces provide a broad view of the water for displaying urban landscapes. Waters gave birth to cities and urban culture, so most waterfront spaces have a unique historical flavor and are carriers of historical memory [20]. In addition, waterfront spaces also provide residents with unique types of activities, 
such as fishing and boating. Waterfront spaces are especially universal in water town cities in southern China. Take Hangzhou as an example. The eastern plain where Hangzhou's main urban area is located is crisscrossed with rivers and scattered with large and small lakes. There are more than 400 rivers in the city, with bodies of water, including rivers, lakes, seas, and streams.

Under this context, this study selected the waterfront open space of the Gongchen Bridge Section of the Grand Canal as a typical research object. Firstly, the activity characteristics of the elderly were surveyed through observation and semi-structured interviews, and the subjective satisfaction of the elderly with the waterfront spaces was investigated. Then, through correlation and principal component analysis, the favorable and unfavorable factors for the elderly in this area were summarized. Five common factors affecting the satisfaction of the elderly were obtained. After that, suggestions suitable for the elderly were proposed and ranked by the level of importance.

\section{Methodology and Case Study}

\subsection{Case Selection}

As the world's longest man-made canal, the Grand Canal is a vast waterway system in the north-eastern and central-eastern plains of China, running from Beijing in the north to Hangzhou in the south (Figure 1) [21]. The Grand Canal is one of the greatest hydraulic projects in human history, stretching $1794 \mathrm{~km}$ and linking five of China's main river basins. Constructed in sections from the 5th century AD onwards, it was conceived as a unified means of communication for the Empire for the first time in the Sui Dynasty (7th century AD). It was a pillar for the economy and provided social stability and government functions in ancient China and was added to the list of World Culture Heritage on 22 June 2014.

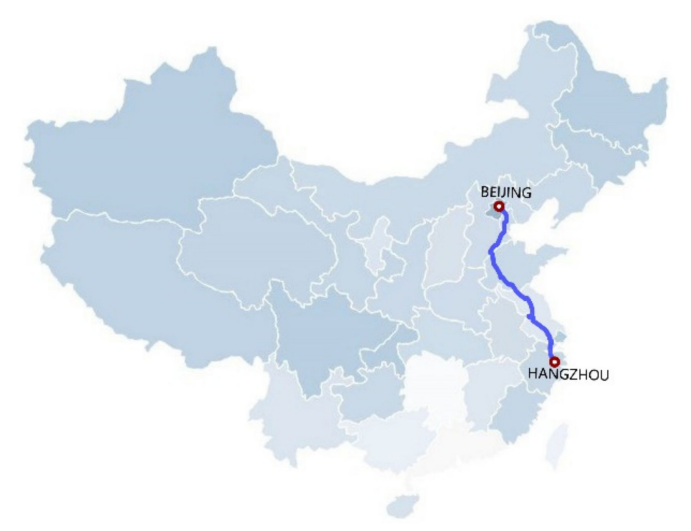

Figure 1. Map of the Grand Canal.

The Gongchen Bridge Section is located in the core region of the Gongshu District in Hangzhou City and is positioned in the northern part of the Hangzhou Grand Canal (Figure 2). Regarding the general layout, the center of the section is the Gongchen Bridge, and the neighboring area, the west coast, consists of historical and industrial heritage protection districts, while many public citizen amenities converge on the east coast, including Yunhe Square and educational buildings (Figure 3). There is an array of residences and relocation houses. Thus, the waterfront open space has a strong residential atmosphere in this section, especially with the high concentration of elderly active users. For thousands of years of history, the Gongchen Bridge Section has preserved memories of different eras, although it has undergone a lot of development and been reclaimed by modernization (Figure 4). The Gongchen Bridge region is not only an integrated showcase of the Yunhe culture and a feature of Hangzhou but also a kernel of public service amenities in the Gongshu District. Besides, the waterfront open space in the Gongchen Bridge Section is an important communal place for outdoor activities. 


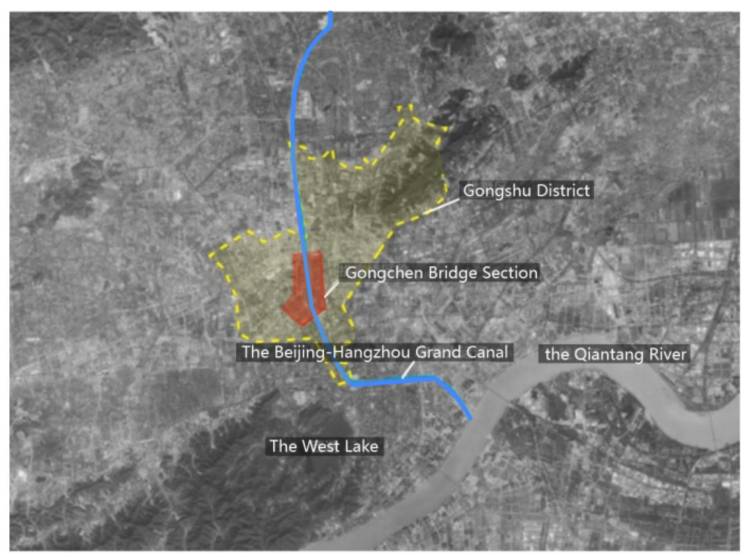

Figure 2. Location relationship of the Gongchen Bridge Section.

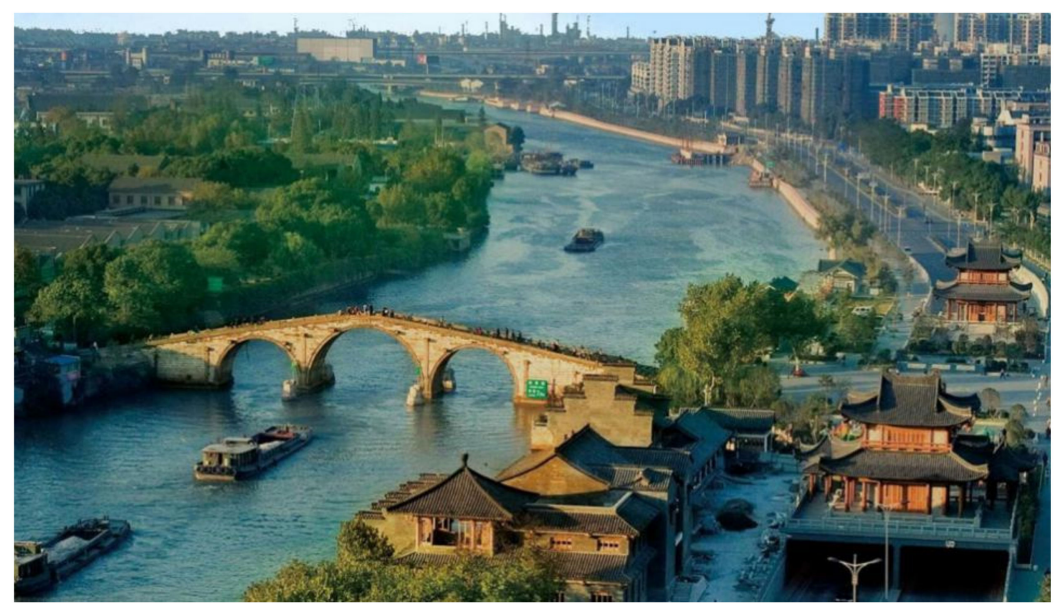

Figure 3. Aerial photo of Gongchen Bridge.

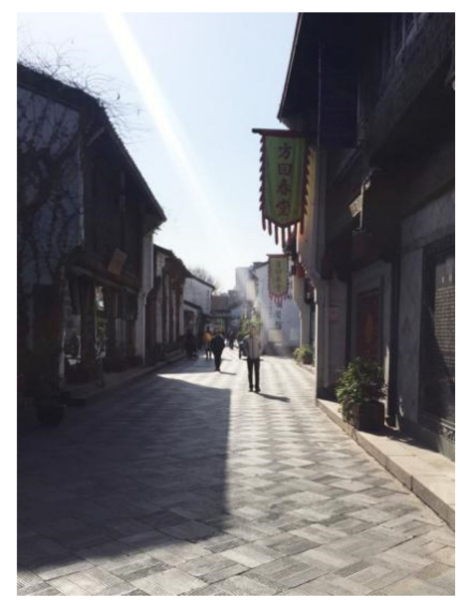

Figure 4. Qiaoxi historic street view.

Due to the large differences at different locations within the section, the research aimed to divide the whole waterfront open space in this section into 12 subsections for further investigation and comparative analysis based on the location, configuration, and continuity of each space (Figure 5, Figure 6 and Table 1). 


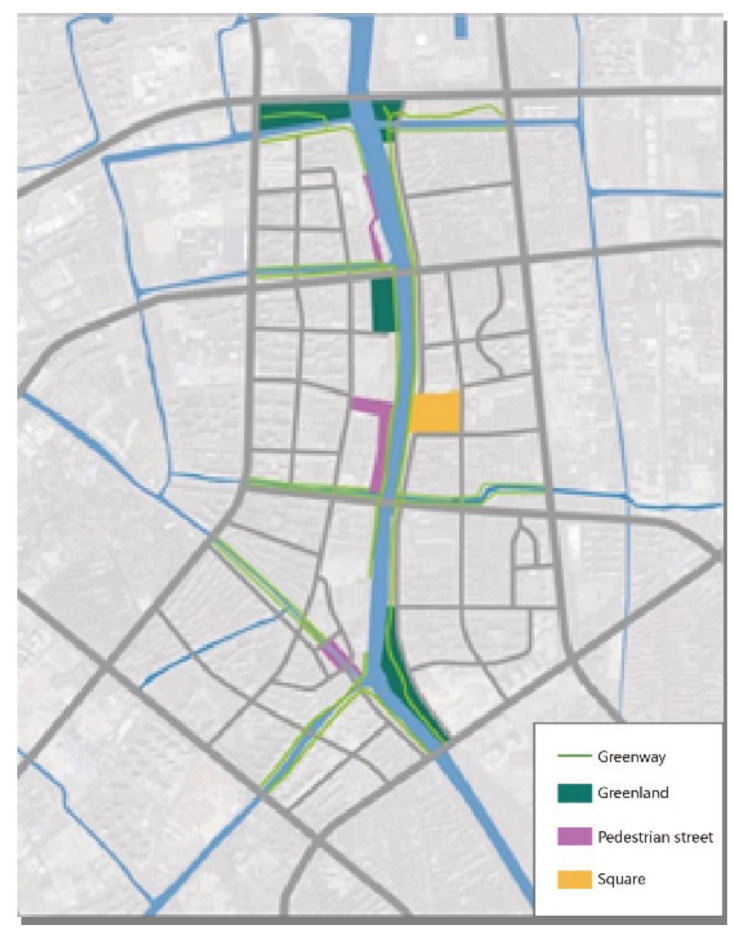

Figure 5. The space types of the study case.

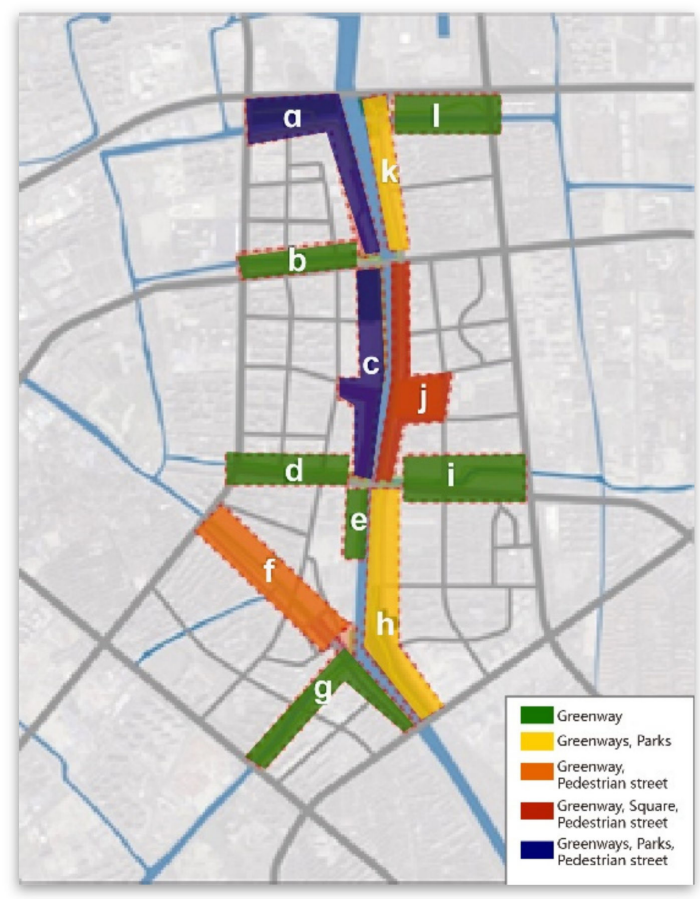

Figure 6. Diagram of sections. 
Table 1. Basic information on each section.

\begin{tabular}{|c|c|c|c|}
\hline Space Type & Section Name & Space Type & Section Name \\
\hline Greenway & $\begin{array}{l}\text { e\# Oil Plant Section } \\
\text { g\# Yuhangtang Section } \\
\text { i\# Yaojiabei Section } \\
\text { 1\# Wayaotou Lane Section }\end{array}$ & $\begin{array}{c}\text { Greenways, } \\
\text { Pedestrian street, Parks }\end{array}$ & $\begin{array}{c}\text { a\# Zheyao Park Section } \\
\text { c\# West Gongchen Bridge Section }\end{array}$ \\
\hline $\begin{array}{c}\text { Greenway, } \\
\text { Pedestrian street }\end{array}$ & f\# Xiaohe Straight Street Section & $\begin{array}{c}\text { Greenway, } \\
\text { Pedestrian street, } \\
\text { Square }\end{array}$ & j\# The Canal Square Section \\
\hline
\end{tabular}

* Section names: based on the most symbolic features. On the basis of space type and the number of active users established by field survey, the portions, which possess various types of space, are regarded as the mainstream subsections of the Grand Canal (a\# Zheyao Park Section, c\# West Gongchen Bridge Section, f\# Xiaohe Straight Street, e\# Oil Plant Section, h\# Qingsha Park Section, j\# The Canal Square Section, and k\# Huzhou Street-Shixiang Road Section), while the portions with greenway are deemed to be the tributary subsections of the Grand Canal (b\# Hengtong River Section, d\# Liantong River Section, e\# Oil Plant Section, g\# Yuhangtang Section, i\# Yaojiabei Section, and l\# Wayaotou Lane Section).

\subsection{Methodology}

\subsubsection{Activity Record}

Observation means that researchers watch subjects directly with accessory tools based on research targets, syllabuses, and tables to obtain information. Observers always utilize modern apparatuses and devices for auxiliary observation, such as cameras, recorders, and micro vidicons [22]. From July 2017 to February 2018, researchers selected one working day and one rest day without rain every season, observed for ten minutes during three active periods, and recorded the number of all active users and elderly active users, as well as the activity types of the elderly and the number of participants carrying out each one. In addition, two rainless working days were selected to record the changes in the number of people in a day at $\mathrm{j} \#$ The Canal Square Section and the $\mathrm{d} \#$ Liantong River Section.

Statistics indicated that 6:00-8:00 am, 2:00-4:00 pm, and 5:00-8:00 pm were the three most active periods. The total number of participants was 9768 , among which the elderly accounted for $61.1 \%$, of which $59.1 \%$ were males, and $40.9 \%$ were females. The proportions of aged activities in different sections are shown in Figure 7. It was found that the number of middle-aged and elderly people in the waterfront space accounted for nearly two-thirds of the total, and the proportion of the elderly in tributaries of the canal was the highest, while the proportion of elderly people in j\# The Canal Square Section and c\# West Gongchen Bridge Section was lower than in other sections due to more tourists, but still exceeded 50\%, which resembles most public spaces in Chinese cities [23-25]. Due to the deteriorating physical condition of the elderly, daily walking, exercise, and socialization are more necessary for them. Meanwhile, as the elderly possess more leisure time after retirement, they are much more likely to be active in such public spaces (especially during the working day) than younger people [10]. 


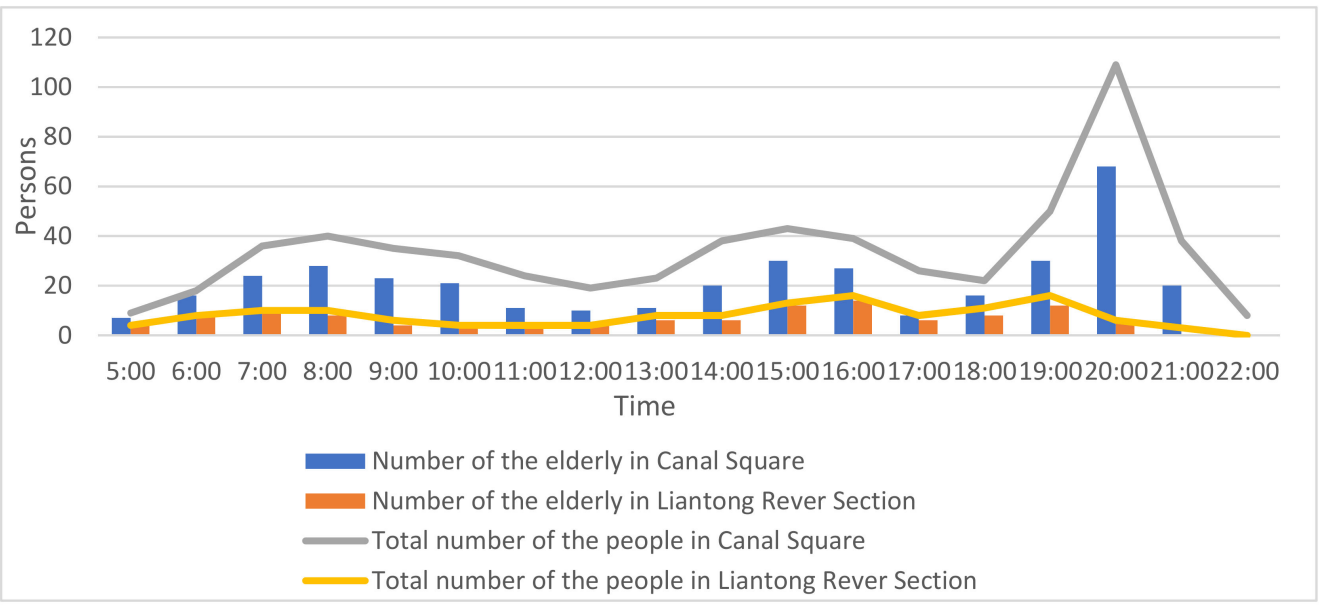

Figure 7. Changes in the amount of activity during a day.

\subsubsection{Activity Survey}

The basic activity survey was conducted through "semi-structured" interviews. Semi-structured interviews are verbal interchanges where one person, the interviewer, attempts to elicit information from another person by asking questions. Even though interviewers tend to prepare a list of predetermined questions, in-depth, semi-structured interviews usually unfold in a conversational manner offering participants the chance to pursue issues that they feel are important [24]. A total of 185 questionnaires were distributed to the elderly (excluding tourists) who were active in the waterfront open space in different subsections of the Gongchen Bridge Section on two chosen days: Thursday, 16 September and Saturday, 18 September, with the largest number in the Canal Square section and the west section of Gongchen Bridge. Due to the semi-structured interviews, the questionnaire recovery rate was $100 \%$, and 178 valid questionnaires were obtained when questionnaires with incomplete answers were eliminated.

The density of the elderly participating in various activity types in different sections is signified in Figure 8. It shows that the activity density varied greatly in different sections. J\# Canal Square and the west section of c\# Gongchen Bridge had the highest activity densities, while the activity densities of e\# Oil Factory and l\# Huayaotou Lane were the lowest (Figure 9). Regarding activity type, the diversity of activities varied between different sections (Figure 9): there were more than ten kinds of activities, including walking birds, taijiquan and square dancing in the mainstream sections like j\# The Canal Square Section and c\# West Gongchen Bridge Section, while in the branch sections, such as e\# Oil Plant Section and l\# Wayaotou Lane Section, there were only basic activities, like walking and taking care of children. Among all the activities, square dancing and walking were the most frequent.

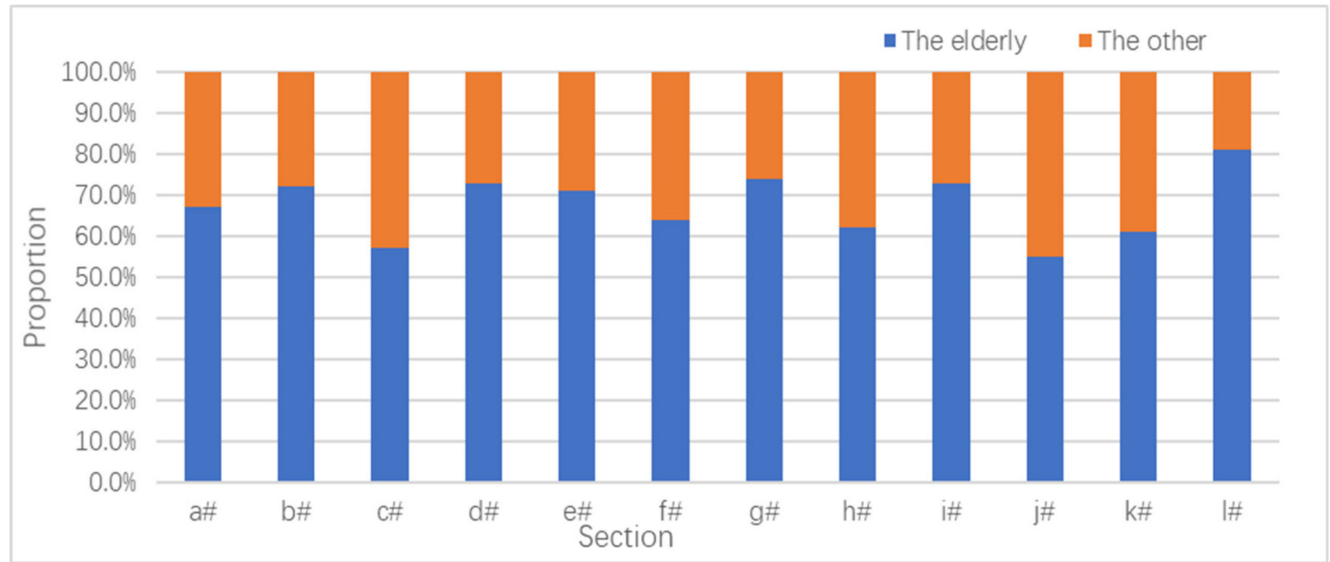

Figure 8. The proportion of elderly people in different sections. 


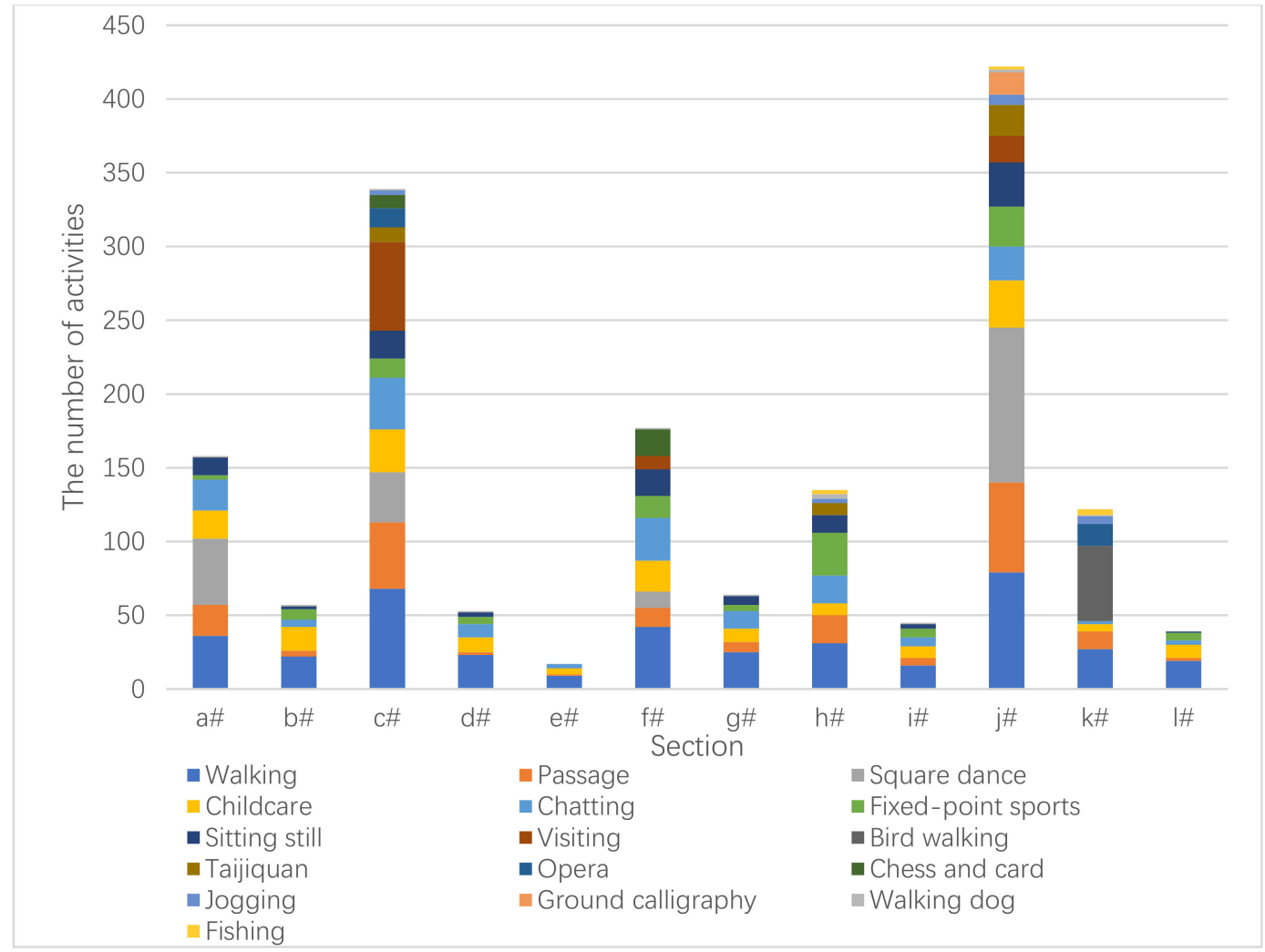

Figure 9. The number of participants in different types of activities in each section. ${ }^{*}$ Number of activities: selected two typical days in each season (three in total), recorded the number of persons for ten minutes from 6:00-8:00 am, 2:00-4:00 pm, and 7:00-9:00 pm, and divided the sum by six to get the average number of persons per day.

There are three main reasons for this difference:

1) The diversity of spaces is different. There are greenways, pedestrian streets, and parks in sections with high activity density, such as c\# West Gongchen Bridge Section, while greenway is the only space type in sections with low activity density, such as e\# Oil Plant Section and l\# Wayaotou Lane Section.

2) The accessibility of the space of each section is different. Compared with the tributaries, the accessibility of the waterfront open space in the main section is better because the waterfront promenade in this section is provided with a pedestrian channel leading to the road or other surrounding spaces.

3) The public facilities in the spaces of each section are different. There are pavilions, seats, corridors, public toilets, and fitness equipment in the sections with high activity density, such as j\# The Canal Square Section and c\# West Gongchen Bridge Section. However, there are only pavilions and seats in the sections with low activity density, such as e\# Oil Plant Section and l\# Wayaotou Lane Section.

\subsubsection{Satisfaction Research}

A Likert scale was used to design a satisfaction questionnaire (Table 2). The respondents were asked to make semantic judgments of "very satisfied", "basically satisfied", "average", "relatively dissatisfied", and "very dissatisfied" about various factors according to their subjective feelings. Different semantic values were assigned: very satisfied $=5$ points, basically satisfied $=4$ points, average $=3$ points, relatively dissatisfied $=2$ points, and very dissatisfied $=1$ point. 
Table 2. Quantitative criteria for satisfaction evaluation.

\begin{tabular}{ccc}
\hline Evaluation Value $\mathbf{X i}$ & Evaluation Language & Level \\
\hline $\mathrm{Xi} \leq 1.5$ & Very satisfied & $\mathrm{E} 1$ \\
$1.5<\mathrm{Xi} \leq 2.5$ & Basically satisfied & $\mathrm{E} 2$ \\
$2.5<\mathrm{Xi} \leq 3.5$ & Average & $\mathrm{E} 3$ \\
$3.5<\mathrm{Xi} \leq 4.5$ & Relatively dissatisfied & $\mathrm{E} 4$ \\
$\mathrm{Xi}>4.5$ & Very dissatisfied & $\mathrm{E} 5$ \\
\hline
\end{tabular}

Based on field research of the actual situation and environmental facilities of the waterfront open space and with reference to a list of design criteria for public open spaces for the elderly proposed by Yung et al. [7], the researchers finally selected 25 evaluation factors that were easy for the elderly to identify (Table 3), which could be divided into four levels: the overall space environment, artificial elements, natural elements, and sociocultural elements, based on the "people, architecture, environment" system (Figure 10) [25]. According to the evaluation index system, the age and section positions were attached to the satisfaction questionnaire.

Table 3. Assessment criteria system.

\begin{tabular}{|c|c|c|}
\hline Dimension & Evaluation Factor & Variable \\
\hline \multirow{9}{*}{ The Overall Space Environment } & Space functional layout & $\mathrm{X} 1$ \\
\hline & Overall space atmosphere & $\mathrm{X} 2$ \\
\hline & Hygiene environment & $\mathrm{X} 3$ \\
\hline & Noise environment & $\mathrm{X} 4$ \\
\hline & Space size & $\mathrm{X} 5$ \\
\hline & Space accessibility & $\mathrm{X} 6$ \\
\hline & Space continuity & $X 7$ \\
\hline & Sunshine in winter & $\mathrm{X} 8$ \\
\hline & Shade in summer & X9 \\
\hline \multirow{7}{*}{ Artificial Elements } & Landscape sketch & $\mathrm{X} 10$ \\
\hline & Step ramp setting & X11 \\
\hline & Ground condition & $\mathrm{X} 12$ \\
\hline & Space size & $\mathrm{X} 13$ \\
\hline & Night lighting & $\mathrm{X} 14$ \\
\hline & Fitness facilities & $\mathrm{X} 15$ \\
\hline & Architectural style & $\mathrm{X} 16$ \\
\hline \multirow{4}{*}{ Natural Elements } & Green land & $\mathrm{X} 17$ \\
\hline & River circumstance & $\mathrm{X} 18$ \\
\hline & Riverside relationship & X19 \\
\hline & Microclimate & $\mathrm{X} 20$ \\
\hline \multirow{5}{*}{ Sociocultural Elements } & Cultural history & $\mathrm{X} 21$ \\
\hline & Space characteristics & $\mathrm{X} 22$ \\
\hline & Space safety & $\mathrm{X} 23$ \\
\hline & Commercial form & $\mathrm{X} 24$ \\
\hline & Tourists' interference & $\mathrm{X} 25$ \\
\hline
\end{tabular}




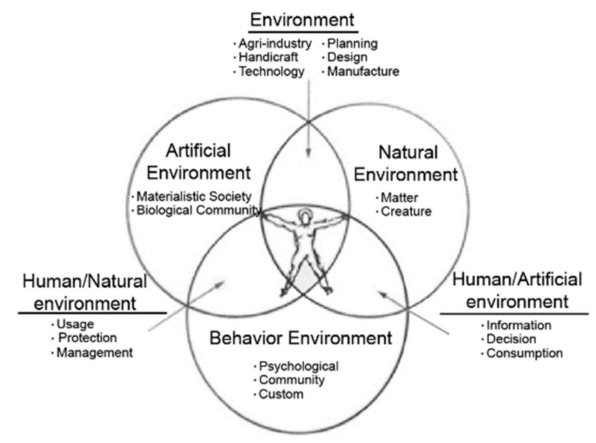

Figure 10. "People, architecture, environment" system.

On Thursday, 9 February 2017, the researchers randomly selected the interviewees in each section to conduct the questionnaire survey. A total of 98 people were interviewed, and 89 valid questionnaires were obtained after the questionnaires with incomplete answers were excluded.

The profiles of the respondents are shown in Tables 4 and 5 below. The ratio of male to female was about 6:4, and the ages were mainly from 60 to 69 years old, accounting for nearly half of everyone interviewed. Both old and new residents were surveyed, and most of the elderly people interviewed lived with their children. The main way they reach the space was by walking, and some choose electric vehicles and public transportation. Of the elderly traveling to the waterfront, $84.8 \%$ arrived there within $20 \mathrm{~min}$. Compared with ordinary neighborhood spaces, the publicity of the waterfront open space is relatively higher [26], and the elderly are willing to spend more to conduct activities in that space.

Table 4. Essential features of the respondents.

\begin{tabular}{|c|c|c|c|c|c|}
\hline \multicolumn{2}{|c|}{ Essential Feature } & \multirow{3}{*}{$\begin{array}{c}\text { Proportion } \\
63.5 \% \\
37.5 \%\end{array}$} & \multicolumn{2}{|c|}{ Essential Feature } & \multirow{2}{*}{$\begin{array}{c}\text { Proportion } \\
23 \%\end{array}$} \\
\hline & Male & & \multirow{5}{*}{ Residence time } & Less than 5 years & \\
\hline Gender & Female & & & 5 to 15 years & $11.2 \%$ \\
\hline \multirow{3}{*}{ Age } & $60-69$ & $49.2 \%$ & & 15 to 25 years & $18.5 \%$ \\
\hline & $70-79$ & $38.5 \%$ & & 25 to 35 years & $19.7 \%$ \\
\hline & $80+$ & $12.3 \%$ & & $35+$ years & $27.5 \%$ \\
\hline \multirow{4}{*}{$\begin{array}{l}\text { Family } \\
\text { formation }\end{array}$} & Live alone & $16.3 \%$ & \multirow{4}{*}{ Education level } & $\begin{array}{c}\text { Junior high school or } \\
\text { lower }\end{array}$ & $63.5 \%$ \\
\hline & In a couple & $28.1 \%$ & & Senior high school & $25.8 \%$ \\
\hline & With children & $45.5 \%$ & & University degree+ & $10.7 \%$ \\
\hline & Others & $10.1 \%$ & & & \\
\hline
\end{tabular}

Table 5. Active characteristics of the respondents.

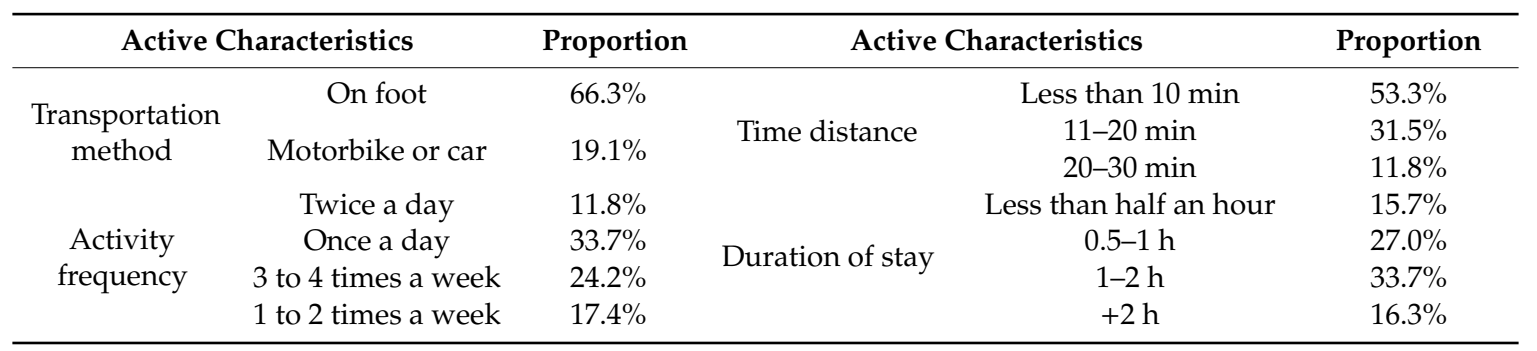

\section{Data Analysis}

\subsection{Data Analysis Method}

Mean analysis, correlation analysis, and factor analysis are common statistical analysis methods. The average value can reflect the concentration trend of the sample accurately. The correlation analysis 
can analyze the correlation between each sample as well as the correlation to the whole. The factor analysis can extract the common factor from the sample variable group and show its contribution level. These methods could be used to quantitatively analyze the spatial use of satisfaction of the elderly in the study.

\subsection{Overall Satisfaction}

The statistical analysis of the mean satisfaction value (Figure 11) showed that the overall satisfaction evaluation of the waterfront open space of the Gongchen Bridge Section was basically satisfactory (3.9 points), while satisfaction with the seating facilities, noise environment, space size, landscape sketch, step ramp setting, ground condition, and architectural style was general (2.5-3.5 points), among which the satisfaction with the seating facilities was the lowest ( 2.8 points). The night lighting and green land were considered satisfactory (3.5-4.5 points), and the satisfaction with tourists' interference was the highest ( 4.8 points).

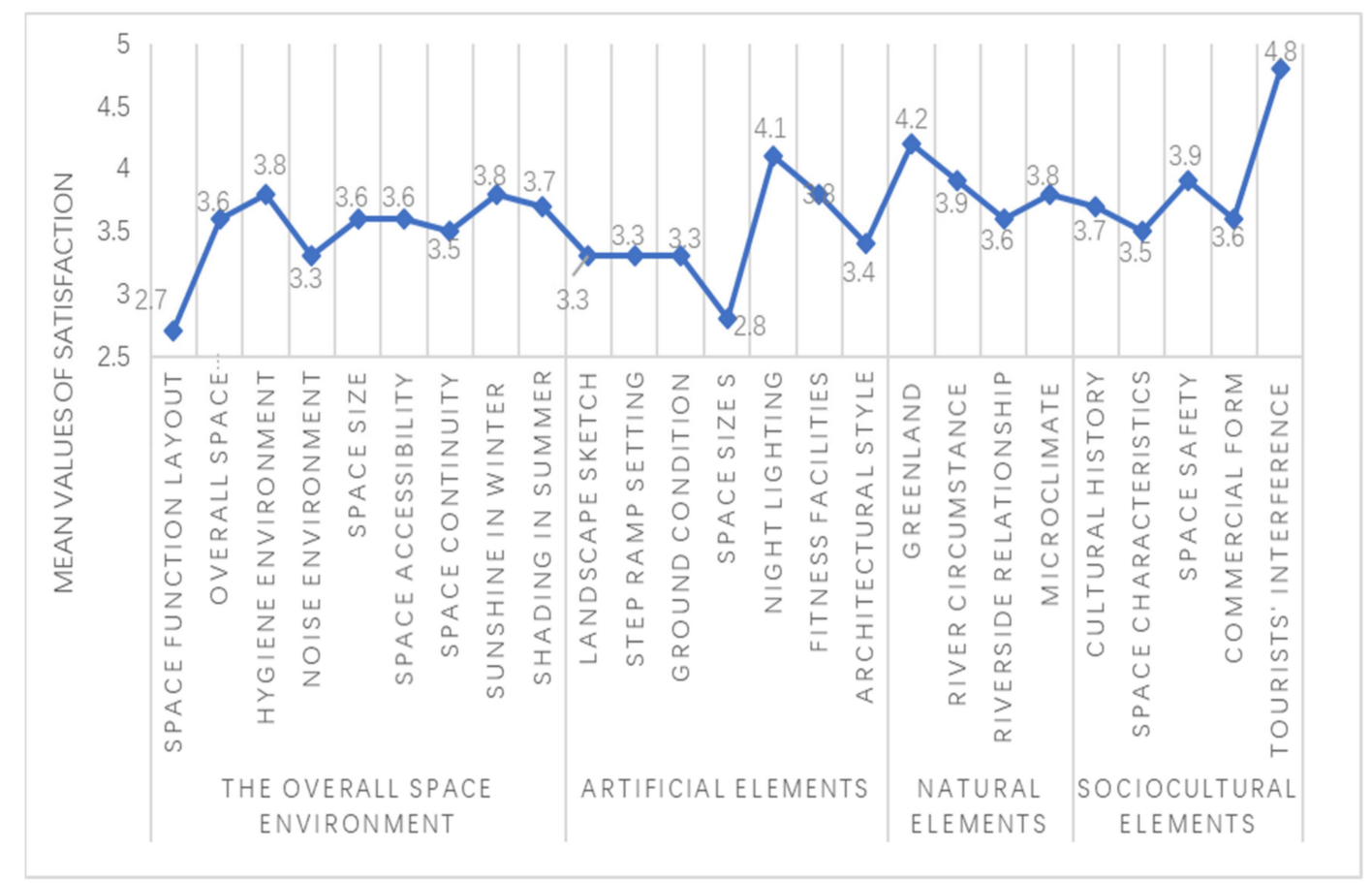

Figure 11. Mean distribution of satisfaction.

An important reason for the elderly to be satisfied with space is that the environmental quality and continuity of the waterfront open space before the renovation was unable to meet the basic needs of the elderly. After transformation, the two have been significantly improved and meet the basic needs of users.

Satisfaction with the seating facilities, noise environment, landscape sketches, step ramp settings, ground conditions, and architectural style was relatively lower. The main reason for the low satisfaction with the seating spaces is their insufficient quantity and uneven distribution; the low noise environment satisfaction is due to the influence of the noise from the road and the cargo ships. The reasons for the low satisfaction with landscape sketches are the lack of overall recognition and memory points and the fact that the elderly do not care about the quality of landscape sketches when doing physical activities. As for the low level of satisfaction with the step ramp settings, the main reason is that there are too many steps, and the elderly also hold the view that the barrier-free facilities are not perfect. The low satisfaction with the ground conditions is mainly due to the uneven pavement of the waterfront walkway, and the architectural style may be related to the vague question. Some old people evaluated 
the current high-rise residential area, while some evaluated the architectural style of the historical blocks, but the overall evaluation of the architectural style of the old people was not so good.

The correlation between each factor and overall satisfaction was analyzed. Calculating the Pearson correlation coefficient showed that at the 0.01 significance level, all factors, except landscape sketches, had a significant normal correlation with overall satisfaction (Table 6). Among the significantly related factors, space accessibility, space continuity, space size, overall space atmosphere, step ramp setting, ground conditions, and space functional layout were most strongly related to overall satisfaction $(r \geq 0.6)$. Because the accessibility of the space is the premise of people's willingness to move in space, and because of degradation in the physiological condition of the elderly, the necessity of this item is higher. Space continuity has a certain relationship with accessibility. On the one hand, continuity can enhance the accessibility of space. On the other hand, due to the linearity of waterfront open space, the proportion of the elderly who take linear walks and slow walks, which require high continuity of space, is high. Space size is the most intuitive manifestation of space type. The richness of space type determines the richness of activity type. In view of the active social needs of the elderly, the impact on the satisfaction of the elderly is also higher. The physical condition of the elderly also makes them pay more attention to the positioning of steps and ramps and the condition of the ground.

Some factors like the continuity of cultural history, space characteristics, noise environment, tourists' interference, and architectural style were less relevant to overall satisfaction, which shows that the elderly have a weaker perception or higher tolerance of these factors.

Table 6. Correlation coefficients of overall satisfaction evaluation.

\begin{tabular}{|c|c|c|c|c|c|}
\hline Variable & Evaluation Factor & $\begin{array}{l}\text { Correlation } \\
\text { Coefficient }\end{array}$ & Variable & Evaluation Factor & $\begin{array}{l}\text { Correlation } \\
\text { Coefficient }\end{array}$ \\
\hline $\mathrm{X} 1$ & $\begin{array}{c}\text { Space functional } \\
\text { layout }\end{array}$ & $0.606^{* *}$ & X14 & Night lighting & $0.582 * *$ \\
\hline $\mathrm{X} 2$ & $\begin{array}{l}\text { Overall space } \\
\text { atmosphere }\end{array}$ & $0.653^{* *}$ & X15 & Fitness facilities & $0.556^{* *}$ \\
\hline $\mathrm{X} 3$ & $\begin{array}{c}\text { Hygiene } \\
\text { environment }\end{array}$ & $0.548^{* *}$ & X16 & Architectural style & $0.318^{* *}$ \\
\hline $\mathrm{X} 4$ & Noise environment & $0.456^{* *}$ & X17 & Green land & $0.554^{* *}$ \\
\hline$X 5$ & Space size & $0.654^{* *}$ & X18 & River circumstance & $0.502 * *$ \\
\hline X6 & Space accessibility & $0.731^{* *}$ & X19 & $\begin{array}{l}\text { Riverside } \\
\text { relationship }\end{array}$ & $0.553 * *$ \\
\hline$X 7$ & Space continuity & $0.710^{* *}$ & $\mathrm{X} 20$ & Microclimate & $0.577^{* *}$ \\
\hline $\mathrm{X} 8$ & Sunshine in winter & $0.511^{* *}$ & $\mathrm{X} 21$ & Cultural history & $0.498^{* *}$ \\
\hline X9 & Shade in summer & $0.528^{* *}$ & $\mathrm{X} 22$ & $\begin{array}{c}\text { Space } \\
\text { characteristics }\end{array}$ & $0.485 * *$ \\
\hline $\mathrm{X} 10$ & Landscape sketch & $0.374^{*}$ & $\mathrm{X} 23$ & Space safety & $0.560 * *$ \\
\hline $\mathrm{X} 11$ & Step ramp setting & $0.617^{* *}$ & $\mathrm{X} 24$ & Commercial form & $0.507^{* *}$ \\
\hline $\mathrm{X} 12$ & Ground condition & $0.608^{* *}$ & $\mathrm{X} 25$ & $\begin{array}{c}\text { Tourists' } \\
\text { interference }\end{array}$ & $0.323^{* *}$ \\
\hline $\mathrm{X} 13$ & Seating facilities & $0.515^{* *}$ & & & \\
\hline
\end{tabular}

* Significant at the 0.05 level, ${ }^{* *}$ Significant at the 0.01 level.

\subsection{Impact Factor Analysis}

The research introduced a factor analysis method to analyze the impact of single factors and common factors on the satisfaction evaluation. According to the KMO (Kaiser-Meyer-Olkin) and Bartlett's tests (Table 7), the KMO value was 0.649, the approximate chi-square value was 2226.576, the degree of freedom (df) was 300, and the significance (Sig) probability value was 0.000 , less than 0.05 . These were sufficient to show that there were common factors in the overall correlation matrix, and the test results showed that the problem was applicable to factor analysis. 
Table 7. KMO and Bartlett's test.

\begin{tabular}{ccc}
\hline \multicolumn{2}{c}{ Kaiser-Meyer-Olkin Measure of Sampling Adequacy } & $\mathbf{0 . 6 4 9}$ \\
\hline & Approx. chi-square & 2226.476 \\
Bartlett's test of sphericity & degree of freedom (df) & 300.00 \\
& Significance & 0.000 \\
\hline
\end{tabular}

Table 8 shows the common factor variance, indicating the explanatory ability of single factors related to the original variable, that is, the influence ability of each factor on the satisfaction evaluation. It indicated that space accessibility, overall space atmosphere, green land, and space continuity were more influential in satisfaction appraisal, and, on the contrary, noise environment, architectural style, shade in summer, tourists' interference, and space configuration were less so.

Table 8. Common factor variance.

\begin{tabular}{cccccc}
\hline Evaluation Factor & Initial & Extraction & Evaluation Factor & Initial & Extraction \\
\hline Tourists' interference & 1.000 & 0.565 & Night lighting & 1.000 & 0.885 \\
Overall space atmosphere & 1.000 & 0.932 & Fitness facilities & 1.000 & 0.749 \\
Hygiene environment & 1.000 & 0.788 & Architectural style & 1.000 & 0.695 \\
Noise environment & 1.000 & 0.697 & Green land & 1.000 & 0.928 \\
Space size & 1.000 & 0.820 & River circumstance & 1.000 & 0.870 \\
Space accessibility & 1.000 & 0.935 & Riverside & 1.000 & 0.757 \\
Space continuity & 1.000 & 0.917 & relationship & 1.000 & 0.804 \\
Sunshine in winter & 1.000 & 0.774 & Cultural history & 1.000 & 0.823 \\
Shade in summer & 1.000 & 0.684 & Space characteristics & 1.000 & 0.862 \\
Landscape sketch & 1.000 & 0.786 & Space safety & 1.000 & 0.777 \\
Step ramp setting & 1.000 & 0.747 & Commercial form & 1.000 & 0.849 \\
Ground condition & 1.000 & 0.820 & Tourists' interference & 1.000 & 0.661 \\
Seating facilities & 1.000 & 0.720 & & &
\end{tabular}

Analytical method: The principal component analysis (PCA).

After rotation, the factor load matrix was obtained, and the factors with an eigenvalue greater than 1 were extracted and required a comprehensive contribution rate of more than $75 \%$. Five common factors were obtained (set as F1, F2, F3, F4, and F5), whose cumulative contribution rate reached 79.38\% (Table 9).

The factor loading for F1, related to the hygiene environment, noise environment, sunshine in winter, shade in summer, green land, river circumstance, and microclimate, was much larger, so it is rational to summarize it as an environmental factor. The factor loading for F2, related to the overall space atmosphere, space size, night lighting, fitness facilities, and riverside relationship, was much larger, so it is justified to summarize it as a functional factor. F3 had a large load for the space function layout, space accessibility, space continuity, step ramp setting, and ground condition, all of which can be summarized as traffic factors. The factor loading for F3, related to space function layout, space accessibility, space continuity, step ramp setting, and ground condition, was much larger, so it can be summarized as traffic factors. The factor loading for F4 was heavily impacted by the cultural history, space characteristics, space safety, commercial form, and tourists' interference and was much larger, and they can be summarized as sociocultural factors. F5 was loaded with landscape sketches and architectural styles, which can be summarized as visual factors. 
Table 9. Factor load matrix after rotation.

\begin{tabular}{|c|c|c|c|c|c|c|c|}
\hline & \multirow{2}{*}{ Public Factors } & \multirow{2}{*}{ Evaluation Factors } & \multicolumn{5}{|c|}{ Components } \\
\hline & & & F1 & F2 & F3 & F4 & F5 \\
\hline \multirow{7}{*}{ F1 } & \multirow{7}{*}{$\begin{array}{c}\text { Environmental } \\
\text { Factors }\end{array}$} & Hygiene environment & 0.156 & -0.037 & 0.049 & -0.028 & -0.093 \\
\hline & & Noise environment & 0.268 & 0.013 & -0.140 & 0.005 & -0.246 \\
\hline & & Sunshine in winter & 0.203 & -0.065 & -0.017 & -0.030 & -0.003 \\
\hline & & Shade in summer & 0.195 & -0.065 & -0.026 & -0.002 & -0.042 \\
\hline & & Green land & 0.255 & -0.043 & -0.079 & -0.062 & 0.022 \\
\hline & & River circumstance & 0.204 & -0.028 & -0.062 & -0.065 & 0.103 \\
\hline & & Microclimate & 0.149 & -0.052 & 0.082 & -0.083 & 0.015 \\
\hline \multirow{6}{*}{$\mathrm{F} 2$} & \multirow{6}{*}{$\begin{array}{l}\text { Functional } \\
\text { Factors }\end{array}$} & Overall space atmosphere & -0.066 & 0.219 & 0.035 & -0.061 & -0.008 \\
\hline & & Space size & -0.067 & 0.233 & -0.012 & -0.022 & -0.041 \\
\hline & & Seating facilities & 0.004 & 0.266 & -0.196 & 0.058 & -0.086 \\
\hline & & Night lighting & 0.021 & 0.276 & -0.186 & -0.017 & 0.009 \\
\hline & & Fitness facilities & -0.047 & 0.249 & -0.015 & -0.031 & -0.156 \\
\hline & & Riverside relationship & -0.097 & 0.204 & 0.056 & -0.100 & 0.102 \\
\hline \multirow{5}{*}{ F3 } & \multirow{5}{*}{$\begin{array}{c}\text { Traffic-related } \\
\text { Factors }\end{array}$} & Space functional layout & -0.101 & -0.061 & 0.324 & -0.087 & 0.128 \\
\hline & & Space accessibility & -0.038 & -0.028 & 0.226 & -0.024 & 0.009 \\
\hline & & Space continuity & -0.049 & -0.059 & 0.234 & -0.049 & 0.144 \\
\hline & & Step ramp setting & -0.014 & -0.027 & 0.266 & -0.065 & -0.111 \\
\hline & & Ground condition & 0.048 & -0.032 & 0.214 & -0.018 & -0.389 \\
\hline \multirow{5}{*}{$\mathrm{F} 4$} & \multirow{5}{*}{$\begin{array}{l}\text { Sociocultural } \\
\text { Factors }\end{array}$} & Cultural history & -0.076 & -0.083 & 0.135 & 0.128 & 0.065 \\
\hline & & Space characteristics & -0.014 & 0.008 & -0.152 & 0.399 & -0.185 \\
\hline & & Space safety & -0.035 & -0.004 & -0.093 & 0.403 & -0.281 \\
\hline & & Commercial form & -0.071 & -0.068 & -0.023 & 0.245 & 0.179 \\
\hline & & Tourists' interference & -0.040 & -0.042 & -0.108 & 0.293 & 0.140 \\
\hline \multirow{2}{*}{ F5 } & \multirow{2}{*}{ Visual Factors } & Landscape sketch & -0.036 & -0.057 & 0.155 & -0.112 & 0.427 \\
\hline & & Architectural style & 0.012 & 0.009 & -0.104 & 0.023 & 0.410 \\
\hline \multicolumn{3}{|c|}{ Cumulative contribution $\%$} & 21.825 & 19.360 & 17.073 & 14.727 & 6.395 \\
\hline
\end{tabular}

\section{Results}

Through factor analysis, it can be seen that environmental factors are the most important factors affecting the overall subjective satisfaction with waterfront open spaces, followed by functional factors and traffic-related factors, with sociocultural and visual factors having a weak impact on the evaluation of the overall subjective satisfaction with waterfront open spaces.

Among the factors regarding the environment, the noise environment, green condition, and river conditions have a great influence on satisfaction. Some elderly people are particularly sensitive to noise due to the deterioration of their bodily functions [27], and as Wen [15] concluded, in neighborhood greenery, elderly people were sensitive to connectivity, air quality, and noise. At the same time, the natural ecological environment, especially green and river landscapes, was the favorite environmental element for the elderly in waterfront open spaces, which is the same in the current study. Among elderly French women aging in place, residential satisfaction has been positively related to proximity to green areas [28]. Similarly, in Spanish samples, Rojo-Perez and colleagues found that access to urban parks and green areas was a predictor, albeit weak, of aging people's residential satisfaction [29].

Functional factors, such as night lighting, seating facilities, fitness facilities, and space size greatly affect the satisfaction of the elderly. Night lighting can extend the use time of the waterfront open space and is also an important factor for safety; seating facilities are places to provide rest and facilitate communication among the elderly; fitness facilities can enrich the activities of the elderly and have a greater appeal to them [30], which is consistent with the conclusion of Yanping et al. [17], who found that PA areas would attract the elderly to participate in park activities as different space types are the basis of diverse activities. Space size as an important factor affecting subjective satisfaction has an important impact on the social needs of the elderly.

As for transport, the functional layout, accessibility, and continuity of spaces are factors that make great differences to satisfaction. The accessibility of the space is the premise of people's willingness to move in it, and because of degradation of the physiological condition of the elderly, this requirement is 
higher, just as when Wen [15] mentioned that the accessibility of urban green spaces, especially parks, played a dominant role in affecting the elderly's nature-based recreation. Space continuity has a certain relationship with accessibility. On the one hand, continuity can enhance the accessibility of space. On the other hand, due to the linearity of waterfront open space, the proportion of the elderly who take linear walks and slow walks, which require high continuity of space, is high. Divya [18] validated the significant positive impact of the presence of amenities like paved walkways, benches, toilets, security, free entry, and shading devices along with universal design factors like universal entry, handrails and ramps, maps and signs, and tactile flooring walkways on the perceived attractiveness of recreational open spaces.

\section{Suggestions}

Based on the analysis results, this study puts forward some suitable design suggestions for the elderly regarding the three most important aspects that affect the overall subjective satisfaction of the elderly with waterfront open spaces.

\subsection{Environmental Design}

A waterfront open space suitable for the elderly should have a good natural ecological environment and, at the same time, pay attention to reducing the impact of noise. The following measures can be used:

1) Enhance the natural ecological environment of the waterfront space. Strengthen the sewage management of the river channel and improve the water quality of the canal. The riverbank can be designed as a grassy slope and covered with plants and trees with better hydrophilicity, such as poplar and willow. The roots of the plants can stabilize the soil and increase the water retention of the bank, which can also promote the construction of a sponge city.

2) Reduce the effects of noise. Increase the density of tall trees or build a landscape wall on the side of the road to block the effects of noise, while placing the important waterfront node on the side away from the road. In addition, small quiet rest spaces with strong enclosures can also provide the elderly with the option of avoiding the noise.

\subsection{Functional Design}

A waterfront open space suitable for the elderly should have suitable night illumination and seating facilities, and also pay attention to the design of small and medium-sized spaces. The following measures can be used:

1) Improve the lighting provisions of areas with strong publicity. The design of the lighting environment should avoid the influence of glare and enhance pavement lighting to facilitate the passage of the elderly. According to the preferences of the elderly, more consideration can be given to warm light in the color design of lights.

2) Increase the number of seating facilities. It is recommended to set a rest seat every $20 \mathrm{~m}$ and a rest pavilion every $200 \mathrm{~m}$ (to provide shade and rain protection) along the continuous waterfront walkway. Try to set the seats in a well-ventilated area with sufficient sunshine or a good visual landscape. The seat setting can be combined with point type and group type, which can provide a more intimate seating environment and space for the elderly to communicate. It is better to have a certain type of relief at the back of the seating space, such as plants, buildings, and flowerbeds, to enhance the security of the seating space.

3) Increase the mesoscale space. The type of waterfront open space is often single (mainly based on small-scale waterfront trails), and it is recommended to increase the number of 'medium-sized spaces', that is, spaces with a size that can accommodate between 20 and 50 people at the same time. The mesoscale space can be divided into static activities and dynamic activity areas 
(Figure 12). The dynamic activity area is a certain size (about $50 \mathrm{~m}^{2}-100 \mathrm{~m}^{2}$ ) with a hard surface for activities, such as square dance, tai chi, and ball sports. The smaller static activity area with large shades, bushes, seats, fences, and pavilions, which can accommodate a few elderly people, is a convenient place for the elderly to sit still, read, chat, and carry out other static activities. The mesoscale space can also add canal cultural landscape pieces to increase the harmony of the space. At the same time, the mesoscale space can provide a variety of activity types, which can easily form an aggregation effect and enhance the overall attractiveness of the waterfront open space.

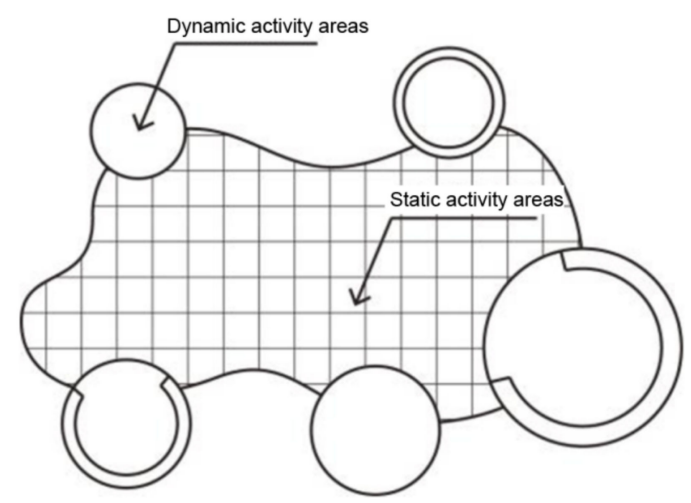

Figure 12. Mesoscale space diagram.

\subsection{Traffic Design}

A waterfront open space suitable for the elderly should have a continuous, safe, and convenient traffic design. Any barrier-free facilities should be fully considered. The specific measures that can be taken include the following:

1) Run through the riverside walkway of the open water space, ensuring maximum space and continuity of traffic.

2) Improve the safety of the road. It is recommended to use a floor covering material that is regular, flat, and not slippery, or a two-material paving method (Figure 13).

3) Reduce the pavement height difference caused by the design. The height difference will hinder the passage of the elderly with mobility difficulties and prams. It is recommended to reduce the pavement height difference caused by the design or set the barrier-free ramp next to the necessary height difference.

4) Plan reasonable parking spaces for bicycles and battery cars. It is recommended to plan parking spots for bicycles and battery cars in areas with high publicity, which can not only solve the chaotic parking problem of bicycles and battery cars but also enhance the publicity of the space.

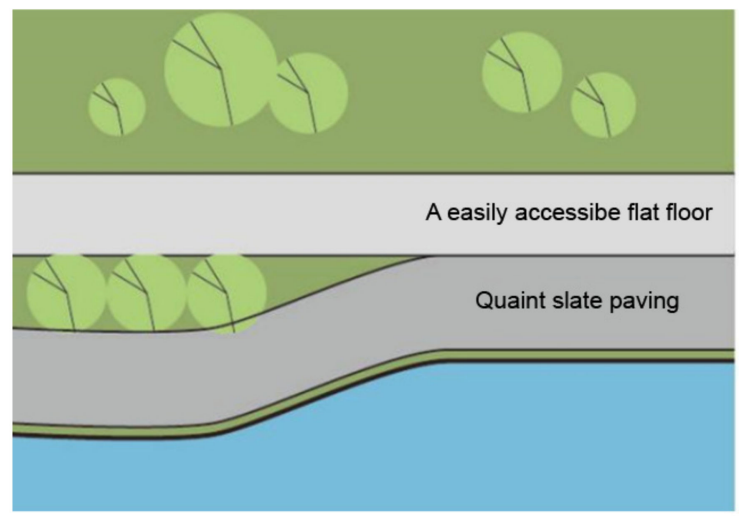

Figure 13. Schematic diagram of parallel pavement. 


\section{Conclusions}

Since China became an aging society in 1999, the aging process with high speed, large base, and aging before wealthy has brought a series of problems for society. Home-based care is the main mode of elderly care in Chinese society. However, present research on the aging-suitability of spaces mainly focused on the interior and exterior environmental conditions of the home, ignoring public open spaces at the regional and urban levels, with a particular lack of research on waterfront open spaces, which are an important type of public open space in Jiangnan Watertown.

The Grand Canal is the first man-made canal in human history. It has a total length of more than $1700 \mathrm{~km}$ and connects Beijing and Hangzhou, two important Chinese cities. This study took the waterfront space of the Gongchen Bridge Section of the Grand Canal as an example for analyzing the suitability for the elderly of waterfront open spaces. The study first used observational and semi-structured interviews to find the activity characteristics of the elderly in this section, and it found that the elderly accounted for nearly two-thirds of the waterfront space's active users. The elderly came here mostly for relaxation and entertainment, mainly after doing exercise. The activities were rich in type, among which square dance and walking were the most frequent activities.

Next, researchers organized a questionnaire survey among the elderly on their subjective satisfaction with the sample waterfront space. It was found that the overall satisfaction with the waterfront open space of the Gongchen Bridge Section was good, and satisfaction with tourists' interference was the highest. Satisfaction with lighting and greenery was good, while satisfaction with the seating facilities was the lowest.

Through correlation and principal component analysis, five common factors affecting the satisfaction of the elderly were obtained: environment, function, transportation, social culture, and vision. Environmental factors were the most important factors affecting the overall subjective satisfaction with the waterfront open space, followed by functional factors and traffic-related factors. Sociocultural and visual factors had a weaker impact on the overall subjective satisfaction assessment.

Finally, some design suggestions suitable for the elderly were proposed regarding three aspects: environment, function, and transportation, which are the most important factors affecting the overall subjective satisfaction of the elderly with waterfront open spaces. These include the following: creating a good natural ecological environment and reducing the impact of noise, equipping the space with sound night lighting and seating facilities, emphasizing the design of small and medium-sized spaces, making transportation continuous, safe, and convenient, and fully considering any barrier-free facilities.

Under the background of home-based care for the elderly in China, Hangzhou regards the construction of "age-friendly cities" as the core goal of the development of the elderly during the 13th Five-Year Plan period, and strives to promote the construction of an environment suitable for the elderly [4]. Due to their unique geographical location, ecological attributes, and social functions, waterfront open spaces are often important places for the elderly to participate in outdoor activities. Whether it meets the needs of the elderly's outdoor activities is particularly important for Hangzhou to build an elderly-friendly city and to cope with the increasingly severe aging problem in Hangzhou. This study provided empirical research data for the characteristics of the elderly and the subjective feelings of the urban waterfront open space, and provided theoretical support and reference for the design and planning of aging-friendly waterfront open spaces, which could improve the aging-suitability of urban open spaces, increase social participation, and enhance the quality of life of the elderly. It is of profound significance to build a senior-friendly city and deal with the increasingly severe aging problem.

But it must be admitted that this study still had some shortcomings. The number of valid questionnaires in this study was only 89 , which was slightly insufficient. In this study, only one section of the Grand Canal was selected for research, and the geographical breadth could be further improved.

Author Contributions: Conceptualization, M.G.; methodology, Q.D.; software, Q.D.; validation, M.R.; formal analysis, M.G.; investigation, Q.D.; resources, X.L.; data curation, M.G.; writing-original draft preparation, Q.D.; writing-review and editing, M.R.; visualization, M.R.; supervision, X.L.; project administration, X.L.; funding acquisition, X.L. 
Funding: This research received no external funding.

Acknowledgments: The authors appreciate the support from the National Key R\&D Program of China (No. 2018YFC0704806), National Natural Science Foundation of China (No. 51878608), Zhejiang Provincial Natural Science Foundation (No. LY18E080025, Hangzhou Science and Technology Development Plan (No. 20190834M45).

Conflicts of Interest: The authors declare no conflict of interest.

\section{References}

1. Yung, E.H.K.; Ho, W.K.O.; Chan, E.H.W. Elderly satisfaction with planning and design of public parks in high density old districts: An ordered logit model. Landsc. Urban. Plan. 2017, 165, 39-53.

2. United Nations, Department of Economic and Social Affairs, Population Division. World Population Ageing 2015 (ST/ESA/SER.A/390); United Nations: New York, NY, USA, 2015.

3. Chinese Academy of Social Science. Reports on China's Population and Labor; Social Sciences Academic Press: Beijing, China, 2019.

4. Ministry of Civil Affairs. Statistical Report on Social Service Development; Ministry of Civil Affairs: Beijing, China, 2016. Available online: http://www.mca.gov.cn/article/sj/tjgb/201708/20170815005382.shtml (accessed on 3 September 2019).

5. Schwanen, T.; Paez, T. The mobility of older people-An introduction. J. Transp. Geogr. 2010, 18, 591-595. [CrossRef]

6. Rantanen, T.; Portegijs, E.; Viljanen, A.; Eronen, J.; Saajanaho, M.; Tsai, L.-T.; Kauppinen, M.; Palonen, E.-M.; Sipilä, S.; Iwarsson, S.; et al. Individual and environmental factors underlying life space of older people-Study protocol and design of a cohort study on life-space mobility in old age (LISPE). BMC Public Heal. 2012, 12, 1018. [CrossRef] [PubMed]

7. Yung, E.H.; Conejos, S.; Chan, E.H.; Chan, E.H.W. Social needs of the elderly and active aging in public open spaces in urban renewal. Cities 2016, 52, 114-122. [CrossRef]

8. Thompson, C.W. Urban open space in the 21st century. Landsc. Urban. Plan. 2002, 60, 59-72. [CrossRef]

9. Pasaogullari, N.; Doratli, N. Measuring accessibility and utilization of public spaces in Famagusta. Cities 2004, 21, 225-232. [CrossRef]

10. Philips, D.R.; Siu, O.; Yeh, A.G.O.; Cheng, K.H.C. The impacts of dwelling conditions on older persons' psychological well-being in Hong Kong: The mediating role of residential satisfaction. Soc. Sci. Med. 2005, 60, 2785-2797.

11. Fernández-Portero, C.; Alarcón, D.; Barrios Padura, A. Dwelling conditions and life satisfaction of older people through residential satisfaction. J. Environ. Psychol. 2017, 49, 1-7. [CrossRef]

12. Liu, Y.; Dijst, M.; Faber, J.; Geertman, S.; Cui, C. Healthy urban living: Residential environment and health of older adults in Shanghai. Health Place 2017, 47, 80-89.

13. Zhang, Z.; Zhang, J. Perceived residential environment of neighborhood and subjective well-being among the elderly in China: A mediating role of sense of community. J. Environ. Psychol. 2017, 51, 82-94. [CrossRef]

14. Yan, B.; Gao, X.; Lyon, M. Modeling satisfaction amongst the elderly in different Chinese urban neighborhoods. Soc. Sci. Med. 2014, 118, 127-134.

15. Wen, C.; Albert, C.; Von Haaren, C. The elderly in green spaces: Exploring requirements and preferences concerning nature-based recreation. Sustain. Cities Soc. 2018, 38, 582-593. [CrossRef]

16. Kwan Yung, E.H.; Wang, S.; Chau, C. Thermal perceptions of the elderly, use patterns and satisfaction with open space. Landsc. Urban Plann. 2019, 185, 44-60. [CrossRef]

17. Duan, Y.; Wagner, P.; Zhang, R.; Wulff, H.; Brehm, W. Physical activity areas in urban parks and their use by the elderly from two cities in China and Germany. Landsc. Urban Plann. 2018, 178, 261-269. [CrossRef]

18. Subramanian, D.; Jana, A. Assessing urban recreational open spaces for the elderly: A case of three Indian cities. Urban For. Urban Green. 2018, 35, 115-128.

19. Rosso, A.L.; Auchincloss, A.H.; Michael, Y.L. The urban built environment and mobility in older adults: A comprehensive review. J. Aging Res. 2011, 2011, 1-10. [CrossRef]

20. Keyvanfar, A.; Shafaghat, A.; Mohamad, S.; Abdullahi, M.M.; Ahmad, H.; Derus, N.H.M.; Khorami, M. Sustainable Historic Waterfront Revitalization Decision Support Tool for Attracting Tourists. Sustainability 2018, 10, 215. [CrossRef] 
21. Cai, J.; Peng, J. Introduction of Beijing-Hangzhou Grand Canal and analysis of its heritage values. J. Hydro-Environ. Res. 2019, 26, 2-7. [CrossRef]

22. Kusumawardhani, A.D.; Thamrin, L.; Khiong, B.Y. Analysis of Chinese Tone Mastery: A Case Study of National Junior High School 10 Schools. J. Pendidik. Pembelajaran Khatulistiwa 2015, 4. (In Chinese). Available online: http://jurnal.untan.ac.id/index.php/jpdpb/article/view/9881/9671 (accessed on 3 September 2019).

23. Miao, Z. Urban Public Space Design and Human Behavior Research; Nanjing Agricultural University: Nanjing, China, 2005. Available online: http://kns.cnki.net/kns/detail/detail.aspx?FileName=2006131784.nh\& DbName $=$ CMFD2006 (accessed on 3 September 2019).

24. Longhurst, R. Interviews: In-Depth, Semi-Structured. Int. Encycl. Hum. Geogr. 2009, 580-584. [CrossRef]

25. Liangyong, W. A Ceneral Theory of Architecture, 1st ed.; China Architecture and Building Press: Beijing, China, 1989; pp. 7-13.

26. Juan, W. Design of Sanhe City Waterfront Public Space Based on User's Environmental Behavior Model; Tsinghua University: Beijing, China, 2012. Available online: http://kns.cnki.net/kns/detail/detail.aspx?FileName= 1013017121.nh\&DbName=CMFD2014 (accessed on 3 September 2019).

27. Tian, Y.; Li, L. Epidemiological study of sleep disorder in the elderly. Chin. J. Epidemiol. 2017, 38, $988-992$.

28. Rioux, L.; Werner, C. Residential satisfaction among aging people living in place. J. Environ. Psychol. 2011, 31, 158-169. [CrossRef]

29. Rojo-Perez, F.; Fernandez-Mayoralas, G.; Pozo, E. Envejecer en casa: Los predictores de la satisfaccion con la casa, elbarrion y el vencindario como componentes de la calidad de vida de los myores en Madrid. Rev. Multidiscip. Gerontol. 2000, 10, 222-233.

30. Wang, L.; Yi, Z.; Jiang, Y. Discussion on the Planning of Community Aged Service Facilities. J. North. Jiaotong Univ. 2001, 25, 107-110. [CrossRef]

(C) 2019 by the authors. Licensee MDPI, Basel, Switzerland. This article is an open access article distributed under the terms and conditions of the Creative Commons Attribution (CC BY) license (http://creativecommons.org/licenses/by/4.0/). 